\title{
Interjurisdictional Cooperation through Bargaining: The Case of the Guangzhou- Zhuhai Railway in the Pearl River Delta, China*
}

Jiang $\mathrm{Xu}^{\dagger}$ and Anthony G.O. Yeh*

\begin{abstract}
Interjurisdictional cooperation has emerged as a major recent trend in China in response to challenges from market reforms and globalization. However, given that cities are in fierce competition with one another, interjurisdictional cooperation presents many difficulties for policy making. This paper attempts to examine how cooperative partnerships can be developed, sustained, or even resisted. It uses the Guangzhou-Zhuhai Railway as a case study to explore the institutional configuration of such a practice and to understand how the historical contingencies and path-dependencies in a transitional society interact with intensive bargaining to influence partnership building. It argues that the lack of a formal institutional framework to facilitate horizontal networking forces actors to opt for ad hoc collaborative arrangements. With the objective of making joint projects workable, commitments for cooperation have to be negotiated on a case-by-case basis through extensive bargaining. Although this creates much flexibility in consensus building, it does not guarantee success: success depends on the interplay of inter-ministry politics, interscalar relations, intercity politics and state-market relations. To a certain extent, the Chinese state can go beyond economic logic and shore up its legitimacy by prioritizing development. The post-reform path-dependencies can provide current political leaders with more rather than fewer instruments with which to negotiate interjurisdictional projects, and thus have greater influence over urban and regional economic governance.
\end{abstract}

* We would like to thank the Research Grants Council of Hong Kong (Project Number CUHK 453609) and the Mrs Li Ka Shing Fund and Strategic Research Theme in Contemporary China Studies of the University of Hong Kong for funding this research. We would also like to thank the anonymous reviewers and the editor for their useful comments in revising this paper.

$\dagger$ Department of Geography and Resource Management, The Chinese University of Hong Kong. Email: jiangxu@cuhk.edu.hk.

* Centre of Urban Studies and Urban Planning, The University of Hong Kong. Email: Anthony.Yeh@ hku.hk (corresponding author). 
Keywords: interjurisdictional cooperation; bureaucratic bargaining; Guangzhou-Zhuhai Railway; Pearl River Delta; China

In the past three decades, cities and provinces in China have been in fierce competition with one another for foreign investment and economic growth. ${ }^{1}$ However, in order to address the challenges presented by market reforms and globalization in recent years, there seems to be an emerging trend of cooperation. ${ }^{2}$ Cooperative partnerships, and ways in which they can be developed and sustained, are critical elements of contemporary strategies to improve urban and regional governance. This is particularly true for trans-territorial infrastructure, a vital social and economic resource that configures territorial space and re-articulates regional mobility and trade flow, as well as industrial and residential locations.

China's policy framework is disjointed, ${ }^{3}$ and the functional division of authority among various bureaucracies in combination with economic decentralization has created a high degree of "fragmented authoritarianism." fragmentation has become structurally built in, and has grown increasingly pronounced during the reform period. No single city has authority over any other. This complex set-up provokes conflicting views on how to achieve cooperation in a highly fragmented political environment. On the one hand, some see "consolidation" as an effective tool to organize and control an array of local agencies, and favour strategies of municipal annexation, merger, and consolidation to encourage urban partnership. ${ }^{5}$ On the other hand, there is an argument to promote the "survival of the fittest" and to encourage more direct competition between localities in order to achieve efficiency in regional infrastructure provision. ${ }^{6}$ Between these two extremes is the "governance approach" which stresses the importance of varying institutional and policy frameworks of public-private partnerships and cross-sectoral alliances. ${ }^{7}$

The consolidation approach is excessively bureaucratic and vulnerable to ideological criticism and strong local resistance because it lacks political legitimacy and operates in an authoritarian manner. ${ }^{8}$ The fragmentationist approach, deeply rooted in a neoliberal tradition, leads to hyper-competition between cities. This creates inefficiencies and inequities in service provision such as infrastructure. ${ }^{9}$ Conceptually, the governance approach provides a good institutional framework in regional cooperation and generates benefits which offset some of the costs of

1 Zhao 2002; Xu and Yeh 2005.

2 Zhang and Wu 2006; Luo and Shen 2006.

$3 \mathrm{Wu}, \mathrm{Xu}$ and Yeh 2007.

4 Lieberthal and Oksenberg 1988; Lieberthal and Lampton 1992.

5 Zhang and $\mathrm{Wu} 2004$.

6 Zhao 2002.

7 Zhang and Wu 2004, 25-26.

8 Zhang and $\mathrm{Wu} 2006$.

$9 \mathrm{Xu}$ and Yeh 2005. 
competition. However, the general lack of institutional structures, such as councils of governments, makes this difficult to achieve. ${ }^{10}$ As a result, informal alliances between governments and joint projects are increasingly used for interjurisdictional cooperation. ${ }^{11}$ Joint projects in particular are embarked upon with swift and everincreasing frequency. Reasons for this include the rising degree of polycentricity of city-regions; increasing local discretion; and the growing pressure of globalization and market reforms giving rise to forces that break out of administrative barriers to create denser socio-economic interdependencies among urban regions and development projects approaching or crossing territorial boundaries. Governments formerly concerned with their own policy alternatives and receiving orders and directives from above are now faced with the prospect of having to form alliances.

However, forming partnerships is not an easy task in a highly fragmented policy framework. One way to do so is through extensive bargaining. ${ }^{12}$ This paper attempts to reveal the dynamics of interjurisdictional cooperation through bargaining by using the Guangzhou-Zhuhai Railway (GZR), which has undergone more than 25 years of negotiation since 1985, as a case study. We examine how the historical contingencies and path-dependencies in a transitional society interact with intensive bargaining to influence partnership building. Our major argument is that a deficient institutional structure for horizontal networking forces actors to opt for ad hoc collaborative arrangements. This creates much flexibility but also allows current political forces to have a greater influence over urban and regional governance. GZR is a large cross-boundary project. We have chosen this case because efforts to realize it provide an unusually instructive window on the patterns of influence in regional development politics. GZR required a large commitment of public resources, incurred losses for some interests and promised great benefits for others. The stakes were high, and the struggles over project authorization, planning and implementation drew in many actors who tried to protect their own interests. The GZR case is considered by many Chinese city planners as one of the best known and typical examples of cooperation through bargaining and offers a circumspect appraisal of the institutional configuration and bargaining politics involved in consensus-building. Using GZR as a case study will help us to understand the divergent and ad hoc pathways of interjurisdictional cooperation, and shed light on how to establish responsive institutions for different political and economic entities to sanction economic prosperity as well as to achieve multi-scalar political equanimity through cooperation.

\section{The Institution and Politics of Interjurisdictional Cooperation in China}

Interjurisdictional cooperation was barely possible in China during the prereform period. A frequently asked question is why, given the strong top-down 
control in a centrally-planned economy? Under state socialism, horizontal relationships between cities were not considered important and vertical linkages with central ministries were more prominent. This system was related to the prereform regime of accumulation, where the central state was the primary geographical scaffolding of accumulation and redistribution. Regional projects were undertaken by line ministries, with little urban and interscalar networking. This regime has undergone massive reorganization since economic reform in 1978, and now cities and regions are used as strategic sites for accumulation and regulation. Policies are designed to increase levels of urbanization, encourage intercity collaboration, and create competitive mega-city regions. There are at least two reasons why interjurisdictional relationships have become much more complex and extensive during the reform era. First, the regime shift has generated forces that push new actors (e.g. cities and non-state actors) into more direct contact with each other. The former state system has been penetrated by the market, by international regimes and by the growing discretion of local states. Political agendas are dominated by complex economic and development issues that arise from greater interdependencies and many trade-offs. A large number of cross-boundary issues have emerged creating a growing need for interjurisdictional cooperation, while at the same time there has been a relative decline in the use of hierarchical command and an increase in the use of market mechanisms. Secondly, the needs of administrative entities are legitimized. With economic decentralization, these entities have become powerful organizations in their own right: one city cannot perform an undertaking by compelling others to cooperate. Yet, an institutional structure for city networking has not been established. There is thus a significant increase in the use of negotiation, which further intensifies the process of bargaining. This is most in evidence when a joint project is carried out.

A joint project is a common form of interjurisdictional partnership. It requires the agreement and participation of more than one government in order to proceed. The number of participants complicates a project's decision-making process. Political scientists have observed that joint projects with a high degree of complexity and multiple trade-offs have to be executed via a bureaucratic bargaining system. This bargaining system comprises an enriched and highly complex set of bargaining relationships between agents in different functional systems as well as between different scales of government. ${ }^{13}$ Post-reform conditions have not reduced bargaining, but rather intensified its process. Indeed, bargaining is critical to the functioning of the Chinese economic and political system, especially when there is no mechanism to resolve conflicts between independent localities. In a sense, bargaining allows different localities and bureaucracies to negotiate over resources and to insert their functional importance in urbanregional governance. 
When negotiating with others, a city should theoretically consider its own costbenefit criteria for project acceptance. This forms the basic precondition for considering collaboration. However, there are some unique characteristics that come into play when making policy decisions in China. First, owing to the soft budget constraint syndrome, local governments often go beyond their budgetary and legal constraints and economic logic to mobilize resources aggressively and make arbitrary decisions in a bargaining process. ${ }^{14}$ Secondly, historical contingencies and path-dependencies tend to create externalities for interjurisdictional cooperation. For instance, the traditional socialist principle requires that "local interests should obey national or regional interests." Cities are possibly forced to sacrifice their own potential benefit in order to fulfil regional agendas, even when there is little incentive for them to cooperate. Perhaps even more importantly, the historical legacies of the post-socialist institution continue to affect interjurisdictional cooperation. In many circumstances, cities must coordinate policy but lack the established mechanisms to network horizontally. National laws do not require adjacent cities to cooperate, nor does the central state offer any incentive to forge such cooperation. ${ }^{15}$ This leads to various ad hoc measures being used to resolve conflicts in both the formulation and implementation phases of decision making.

We use four institutional dimensions to reveal the manifold activities of different functional and territorial administrations and their complex interactions. The first dimension is related to inter-ministry politics. The central structure for coordinating regional projects is a legacy of state socialism. It is highly fragmented, being divided into different ministries. Each ministry stipulates a sectoral plan for the infrastructure sector in charge. However, planning and investment decisions have to be made through inter-ministerial networking, where the National Development and Reform Commission (NDRC) and other functional bureaucracies (e.g. finance, highway, railway, planning, environment and land administration) negotiate towards a working consensus. These ministries are constitutionally at the same administrative level and no one ministry has authority over another. This leads to inter-ministerial rivalries and complex political manoeuvring in practice. Although highly fragmented, the central policy system also serves as a buffer since it allows one or a few affected units to postpone a project for substantial periods of time, thus leading to a wide range of measures to heighten coordination and to overcome the fragmentation of authority. ${ }^{16}$ To a certain extent, the central state still serves as an important level of economic regulation. It has also been an essential institutional focal point around which various policies and decisions have been articulated.

The second dimension is interscalar relations. Post-reform transition has profoundly modified inherited scalar arrangements. Previously, the central state 
hegemony was naturalized. Nowadays, many state functions are being rearticulated downwards to local governments, establishing a redefined interscalar regime, through which project planning and investment decisions are negotiated, evaluated and regulated both discursively and materially between different tiers of governments. This policy process is often punctuated by persistent struggles to impose or transform policies, to directly influence the exercise of regulatory power on one or more scales, to escape or bypass the exercise of such power by jumping scales to upper levels, or to influence it through struggles that are conducted in the name of new political and economic legitimacy.

An investigation into the third dimension, intercity politics, reveals the efforts of local state regimes to engage or disengage from particular partnerships and obligations in planning and financing regional transportation projects which cut across jurisdictional boundaries. This is in contrast with the increasing local discretion in planning negotiation, the rising use of locally raised funds to support capital investment, and the politics of distributing investment responsibilities among jurisdictions. It might prove difficult to rely on local planning efforts and funding sources as a means to improve mega-city regions' infrastructure, except to the extent that the regional and municipal interests overlap.

The fourth dimension, state-market relations, needs a careful reading in postreform China. The state has not retreated because of market reform; rather, it continues to play a critical role in economic development. This should not be read as a legacy of state socialism. There has been a substantial change in the nature of state intervention because state function is redefined by the imperative of market development, making the state fundamentally different from before. For example, the state can use market instruments to solve its own crises (e.g. shortage of capital) and to externalize its responsibilities (e.g. infrastructure development invites the participation of non-state actors). This opens up a new window through which to view the high degree of risk-sharing, rights-sharing and obligation-sharing between partners in a joint project.

In the following sections, these four institutional dimensions of interjurisdictional cooperation are used to examine the bargaining process of the GZR project.

\section{Interjurisdictional Cooperation through Bargaining of Chinese Railway Development}

Chinese railways are state-owned. They are provided and controlled by the Ministry of Railways (MOR). Railways also traverse administrative boundaries, and analysing how decisions are made in this field during a railway investment boom will help to reveal the bargaining process of interjurisdictional cooperation. Before studying the case in detail, we will briefly review the normal institutional process in developing a railway, which reflects all four dimensions discussed in the previous section (see Figure 1). 
Figure 1: An Ad Hoc Institutional Arrangement in Developing a Railway through Province-Ministry Cooperation

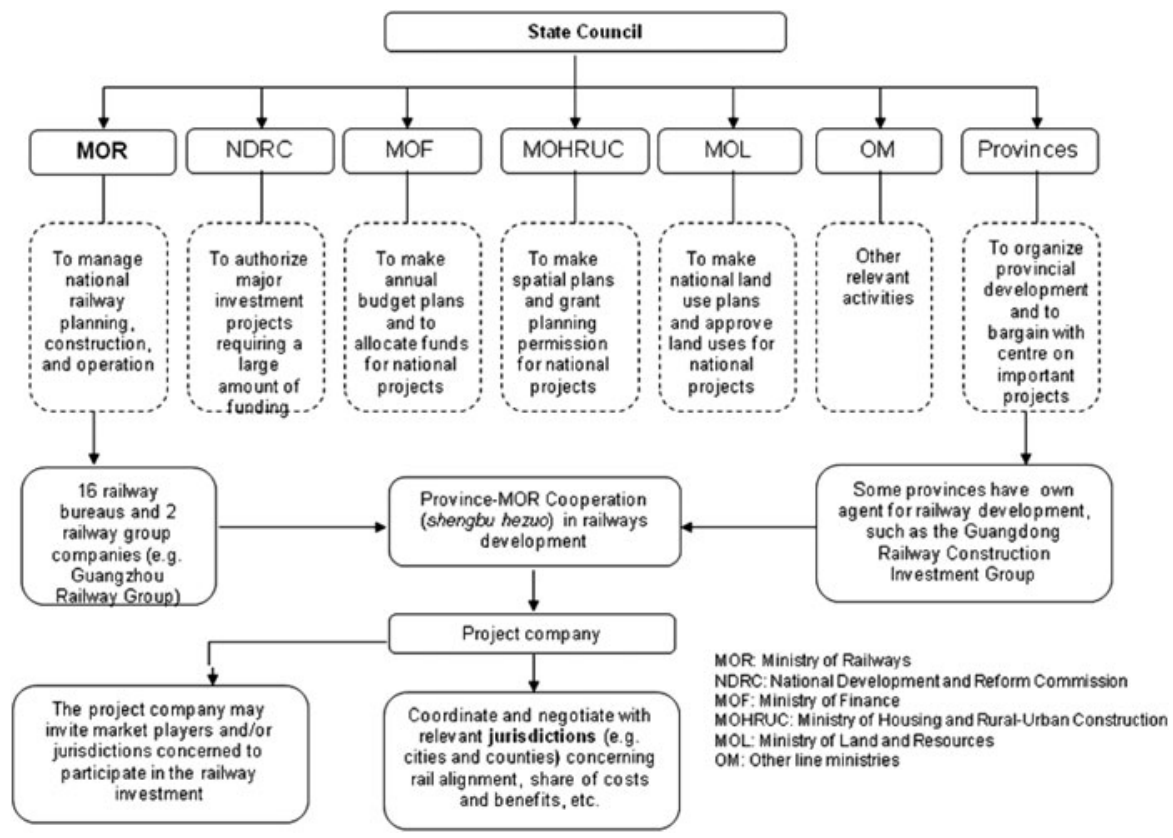

Inter-ministry politics

MOR has complex relationships with other ministries, and in particular with NDRC which is in charge of project approval to ensure that any project is consistent with national plans and policies. ${ }^{17}$ However, NDRC and MOR have policy discrepancies. For instance, NDRC requires that major investment be placed in the western regions of China in accordance with the national "go west" policy. However, MOR would prefer to maximize its return by investing in more prosperous mega-city regions, such as the Pearl and Yangtze river deltas, and becoming the primary shareholder of key projects in these regions.

\section{Interscalar relations}

The monopoly of MOR and the pressure to change this situation has redefined the interscalar relationships of hierarchical governments. MOR has 16 railway bureaus and two railway companies directly under its auspices. It is through these organizations that MOR operates its monopoly. Institutionally, this places MOR in an advantageous position in negotiations with local governments. Localities can initiate a railway plan, but they have to seek the support of 
MOR which monopolizes rail services and profit distribution through its clearing centre. One key strategy for cities is to invite MOR to become the controlling shareholder of a rail project. This is an effective way to guarantee sufficient passengers and cargos.

From the MOR perspective, there are financial reasons for partnering with lower level governments. Prior to 2004, the budget for new railway construction came from a surcharge on freights. Although the total surcharge has increased steadily, it is far from sufficient to cover the expenses of MOR's ambitious Mid-to-Long Term Railway Network Plan. Since 2004, MOR has had to find other sources to raise the necessary funds. As a result, the Province-MOR Agreement (shengbu xieyi 省部协议) (PMA) has increasingly been used to finance railway investment. However, in order to protect its power base, MOR has to negotiate with local governments to ensure that its share of the total investment is not drastically reduced. There is no standard protocol for cooperation and each project entails a different deal, with ad hoc sharing arrangements worked out by the province concerned and MOR. A project company will then be set up, through which both parties negotiate with low-level territorial and bureaucratic actors to decide on critical issues such as line alignment and investment allocation. This negotiation process is critical because any regional project requires the active cooperation of local officials. Normally, it is not easy for local officials to refuse a demand from high-level bureaucrats, but all parties concerned realize that the locales must be persuaded into cooperation; otherwise, they are capable of generating perpetual delays during the construction of a project. ${ }^{18}$ Negotiations for new railways are particularly complex and delicate, as not only do they require the relocation of people and land use changes, but they also often disproportionately benefit those who have contributed the largest share.

\section{Intercity politics}

Bargaining is also intense among the different cities concerned. Negotiations focus on several issues, but particularly on investment allocation and line route. City status plays a key role in intercity politics as Chinese cities are hierarchically organized into five levels: provincial, sub-provincial, prefecture, sub-prefecture, and county. This tiered city status defines two fundamental parameters of intercity cooperation: (1) different governments may not be on equal footing in ranking, causing unbalanced political representation in many regional projects; and (2) government relations are often (re)articulated through a hierarchical structure, while lacking a mechanism to forge horizontal collaboration. To complicate this state of affairs further, other salient features of politics, such as "administrative capital," play a large role in decision making. The 
unofficial system of high-ranking officials or individuals adjoined by guanxi (关 系, personal connections) allows bureaucrats to make personal agreements with the central state or with low-level actors. This can change a policy decision, making conditions favourable for a joint project.

\section{State-market relations}

The state-market relationship in railway development is a tricky one. Non-state investors (e.g. mining companies) have expressed an interest in investing in and running railway lines, ${ }^{19}$ but this is not always workable owing mainly to MOR's monopoly in line construction and service operation. The response from MOR is also unenthusiastic, even though it has said that non-state actors are permitted to invest in the sector in order to relieve MOR of the financial burden of line construction.

\section{Guangzhou-Zhuhai Railway (GZR) ${ }^{20}$}

The Pearl River Delta (PRD) is a polycentric mega city-region in Guangdong. It comprises nine municipalities with a total population of more than 50 million. $^{21}$ Since the economic reforms, PRD cities have been under mounting pressure to take an entrepreneurial stance in order to prosper under intensive intercity competition. Bordering Macau, Zhuhai 珠海 is one of two pioneering special economic zones in the PRD; the other is the more economically vibrant Shenzhen 深圳, located next to Hong Kong. Lagging infrastructure development was perceived as the main cause of Zhuhai's sluggish growth. In 1985, the city's Party secretary proposed to open a rail link from Zhuhai to Guangzhou, providing passenger and cargo services (see Figure 2). The project was first estimated to cost approximately US\$650 million, with a length of 142 kilometres, commencing in Guangzhou and ending in Zhuhai. It would be served by six stations covering the four municipalities it passed through: Guangzhou, Foshan 佛山, Jiangmen 江门 and Zhuhai. A further extension could be added to connect to Macau. In Guangzhou, the track would connect to the national railway system, and its terminal in Zhuhai was expected to link with Gaolan 高栏 Port. ${ }^{22}$ From its first inception in 1985, a number of problems slowed the project down in its planning phase (see Table 1). From interviews conducted with various planners and government officials, we have identified the areas of contention that became the foci of protracted bargaining: the justification; local opposition; investment allocation;

19 Luger 2008.

20 Information in this section, unless otherwise stated, is from several reliable sources including government officials, planners and scholars in Zhuhai, Guangzhou, Foshan, Jiangmen and Beijing. All informants are directly involved in or have studied GZR and have first-hand materials and information. A full list of interviews is available from the authors upon request.

21 Yeung, Shen and Zhang 2005.

22 NDRC 2004. 
Figure 2: Regional Transportation Network in the PRD and the Proposed GZR

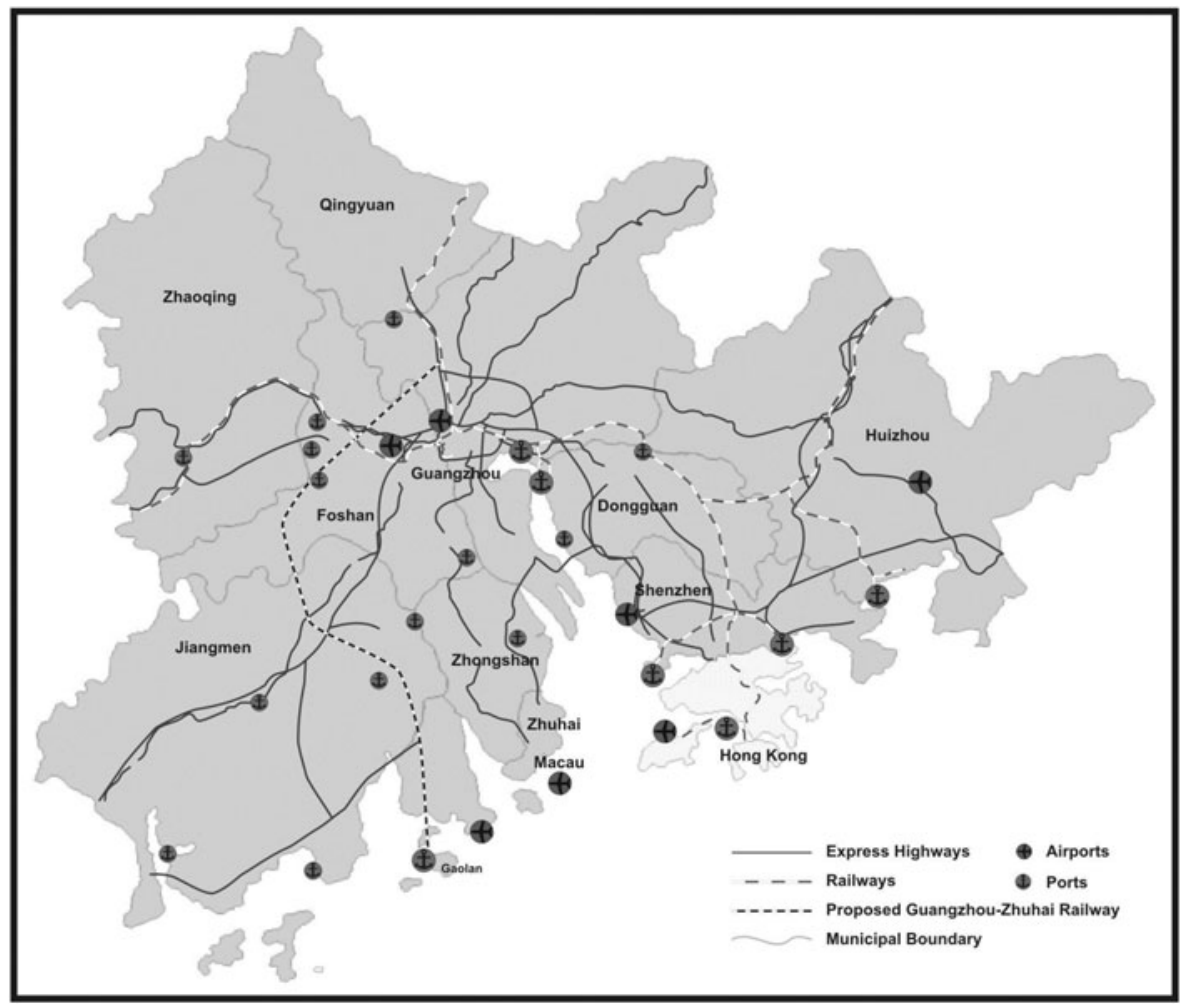

project approval; and the issue of participation of non-state actors. These issues reflect various institutional dimensions of interjurisdictional cooperation.

The justification: why should this railway be built?

The bargaining process over the project's rationales illustrates the sophisticated nature of interscalar politics. GZR was initially proposed by Zhuhai, based on the consideration that Zhuhai was the only city among the five special economic zones and 20 major port cities in China that lacked a railway. Without proper economic justification, there was intense controversy over why this project should be built. Zhuhai's Party secretary was a well-known cadre with an extensive personal network in the bureaucratic system. He was ranked second to Deng Xiaoping in the 1993 "Ten People of the Year in China." He was also a member of the standing committee of the Guangdong Communist Party Committee, the highest decision-making body in Guangdong. Through his connections and liaison with the central government, GZR gained the support of the deputy minister of railways. In 1993, the State Council authorized the project. In 1994, the State 


\section{Table 1: Project Timeline and Major Events of GZR}

\section{Phase I (1985-1999): Early Inception}

1985 Party secretary of Zhuhai proposes to open a rail link from Zhuhai to Guangzhou to provide both passenger and cargo service

1992 Zhuhai's Party secretary becomes member of the standing committee of Guangdong Provincial Party Committee

$1993 \quad$ Project approved by the State Council

$1994 \quad$ Feasibility study approved by the State Planning Commission

1997 Project company formed by Zhuhai, Jiangmen and MOR; construction begins; completion set for 2001

$1998 \quad$ Zhuhai's Party secretary resigns

1999 Construction ceases because of shortage of capital

\section{Phase II (2000-2003): Stalemate}

2000 Another passenger rail, Guangzhou-Zhuhai Light Rail, proposed as one part of the PRD intercity railway network; one deputy governor objects to GZR

$2001 \quad$ Project company carries out a supplementary feasibility study

2002-2004 Zhuhai and Jiangmen's deputies of national and provincial people's congress propose to re-start the construction of GZR

2002-2004 Zhuhai's attempts to lobby the central and provincial governments and to re-negotiate with Jiangmen and Foshan all fail

2003 Zhuhai's attempts to invite investors for GZR fail

\section{Phase III (2003-present): Resumption of Bargaining}

2003 Guangdong's Party secretary decides to develop railways in Guangdong; Zhuhai seizes this chance to lobby Guangdong to include GZR into provincial railways development plan; Guangdong's Party secretary and the railways minister agree to facilitate GZR project under PMA scheme; Guangdong's Party secretary goes to Foshan to elicit their cooperation

2004 Zhuhai successfully lobbies MOR to invest in GZR; GZR designated as one of 9 railway projects under PMA scheme in Guangdong; Zhuhai, Jiangmen and Foshan resume dialogue

2005-2006 Zhuhai, Jiangmen, Foshan, Guangdong and MOR negotiate investment share and route; project re-designed as a cargo rail; proposal fails the national environmental impact assessment and land use permits refused; new feasibility study sent to central ministries for approval

Since 2007 New project company formed; construction completed in 2012; GZR opened for operation end of 2012.

Planning Commission (the predecessor of NDRC) approved the feasibility study. Clearly, in an effort to win project approval, the Zhuhai Party secretary relied on his administrative capital to impose the decision and to bypass the province and other cities concerned by jumping directly to the centre for authorization. Following central approval, Guangdong had to give its consent, but made it clear that the province would not invest in the railway because highways, rather than railways, were seen as the priority for provincial investment. Zhuhai then had to raise the project funds, but failed. In 1998, the Party secretary of Zhuhai resigned from his post, and the project was officially halted in 1999. 
The essence of the problem was that as the project proceeded doubts regarding its financial return grew more intense. Some senior provincial leaders opposed the project, which raised political conflicts. This was especially true towards the latter half of the 1990s, when another new passenger railway line, the GuangzhouZhuhai Express Light Rail, was planned as part of the provincial government's efforts to build a US\$13 billion intercity fast rail network connecting the major cities in the PRD. Beginning construction in 2005 and opening in 2010, this new railway has a distance of 140 kilometres and cost US $\$ 2.52$ billion. It passes through Guangzhou, Foshan, Zhongshan 中山, and Zhuhai, with a branch line from Zhongshan to Jiangmen. ${ }^{23}$ It is a joint project under the PMA scheme between MOR and Guangdong. Those who opposed GZR argued that the new Express Light Rail line would snatch passenger traffic away and would make GZR financially unviable.

Perhaps it was because GZR was so crucial to increasing the accessibility of Zhuhai that the city had a much more optimistic estimate of its financial return which was well above that of the provincial authorities. In this kind of bargaining situation, Zhuhai, the proponent, had to puff up the benefits and tried to influence provincial and central decisions. This was done by using a couple of strategies. First, Zhuhai carried out another feasibility study to demonstrate that there would be sufficient passengers and enough cargo to cover the operating costs of GZR, and that the railway could help to meet the growing transportation demand in the western part of the PRD. Secondly, the city continued to mobilize all kinds of resources to lobby provincial and central authorities for their support. One consequence of this intensified effort was that 69 deputies from the national and provincial people's congress from Zhuhai and Jiangmen jointly proposed to resume the GZR project in 2002. ${ }^{24}$ One interviewee told us that "complex and literally never-ending discussions with provincial and central authorities occurred over the project's feasibility." 25

The breakthrough came in November 2003, when the Party secretary of Guangdong (who was also a member of the Politburo) and the railways minister agreed to speed up railway development in Guangdong through the PMA scheme. Guangdong's Party secretary was concerned that the lagging railway infrastructure would hinder the province's rapidly developing economy. Up until the end of 2004, transportation in Guangdong relied heavily on highways. The total rail length in the province was 1,883 kilometres, accounting for only 2.56 per cent of the total rail length in China and ranking among the bottom four of all provinces. A deputy governor lamented that "this is totally out of proportion with the robust economic growth of Guangdong whose output represents

23 People's Daily. 2002. "Guangdong to build $139.8 \mathrm{~km}$ express railway to Zhuhai." 25 November.

24 Zhuhai tequ bao. 2005. "Xiujian Guang-Zhu tielu, shixian bainian mengxiang" (Build the GuangzhouZhuhai railway, fulfil a 100 year-old dream). 20 May.

25 Interview with Zhuhai government official, Zhuhai, July 2008. 
almost 10 per cent of the national total." 26 The slow growth of its rail infrastructure would place the PRD in a disadvantageous position in the national economic landscape. Thus, the Party secretary ordered provincial departments to devise a Guangdong Railway Development Plan.

The shifting of provincial investment priorities to railroads provided Zhuhai with an unprecedented opportunity to resume GZR. The city swiftly resumed its lobbying of the State Council, MOR, provincial authorities and key leaders. However, several key provincial leaders still disliked the idea owing to Zhuhai's reputation for circumventing provincial and central regulations to construct mega projects without proper authorization. ${ }^{27}$ Zhuhai then decided to propose that GZR would serve mainly as a freight line in order to avoid overlapping with the intercity passenger line. It was argued that a cargo line was needed to complement highway and water transport, and to meet the growing cargo demand resulting from the rapid industrial growth and port development in Zhuhai and Jiangmen. ${ }^{28}$

These persistent efforts finally paid off and Guangdong decided to include GZR in the Railway Development Plan. This decision was taken and agreed upon by the Party secretary, a deputy governor of Guangdong and the railways minister when the three of them took part in a training course at the Party School of the Central Committee of the Communist Party. ${ }^{29}$ Soon after that, the deputy secretary and the mayor of Zhuhai led a delegation to meet the railways minister in Beijing where they reached a consensus that MOR would invest in GZR as a controlling shareholder. ${ }^{30}$ This implies that GZR was upgraded to central project status under the PMA scheme. The railways minister stated that "the line will definitely make a profit because it links up with major ports in Zhuhai and Jiangmen." ${ }^{31}$ In October 2004, Guangdong and MOR officially signed an agreement to speed up railway development in the province and GZR was identified as one of nine railways to be built by 2020 .

It appears from our interviews and preceding discussions that one of the key areas of contention was the economic justification of GZR. During the

26 Yangcheng wanbao. 2007. "Guang-Zhu tielu tizhi gaibian” (Guangzhou-Zhuhai railway changes status). 15 January.

27 One such project is the Lingding Yang Bridge. In 1997, Zhuhai began construction of its own cross-delta Lingding Yang Bridge, which was proposed by its Party secretary in the late 1980s to link Zhuhai and Hong Kong. This project was undertaken without provincial and central approval and without any communication with Hong Kong. It was halted three years later after little progress. The Lingding Yang folly was exceeded by that of the Zhuhai Airport. Opening for flights in 1995, it was built at a cost of more than US $\$ 840$ million, but only operates at less than 5 per cent of its annual capacity of 10 million passengers. Zhuhai Airport was built in accordance with the standards of an international airport for which it had no proper authorization. Today, it is still a domestic airport and has not been granted permission to host international flights. In 2005, the airport owed at least US\$1.5 billion in domestic liabilities, losing a further US\$2.4 million per month.

28 NDRC 2004.

29 Interview with Zhuhai government official.

30 Ibid.

31 Yangcheng wanbao. 2007. "Guang-Zhu tielu tizhi gaibian" (Guangzhou-Zhuhai railway changes status). 15 January. 
negotiation process, interscalar politics is evident between MOR, Guangdong, and Zhuhai, where Zhuhai was fighting with Guangdong and lobbying central ministries (e.g. MOR and NDRC) to justify the economic rationales of GZR. Clearly, there is a redefined interscalar regime, where local governments can play an active role in the negotiation for project authorization and planning. Zhuhai tended to go beyond the economic logic and its budgetary constraints to overemphasize the project's benefits, while Guangdong remained unconvinced by the claimed financial return. The interscalar negotiations resulted in a long bargaining process. Zhuhai's leaders used strategies which were contingent upon their resources and position in the government hierarchy in order to transform policies, to influence the decision-making process, and to jump through scales in order to seek central support. They also utilized the wider social-political-economic contexts (e.g. Guangdong's decision to facilitate railway investment) to promote GZR. Zhuhai compromised on contentious issues too (e.g. giving up the passenger function of GZR). All in all, the city attempted to influence policy decision through persistent struggles to bargain with central and provincial authorities and to legitimize the project in the name of new political and economic legitimacy. In one interview, we were told that "political factors are key, because they reinforce the bargaining power; administrative capital counts, while sometimes cost-benefit analysis counts for nothing." 32

\section{Local opposition}

Another contentious issue was local opposition from cities along the route of GZR. This is a key dimension of both intercity and interscalar politics. Zhuhai and Jiangmen would benefit most from GZR, while Foshan would contribute excessive land resources (in proportion to its benefits). Guangzhou remained indifferent, because it was already an established transportation hub in southern China and the outcome of the GZR proposal would not affect this status either way. ${ }^{33}$ Several rounds of intense negotiations were conducted to redress these imbalances.

In the mid-1990s, Zhuhai's leaders took the initiative to negotiate with the other cities concerned. Guangzhou agreed to build the line but refused to fund this project. Foshan strongly opposed the project as it would not benefit greatly from a new line and the proposed route cut through its city districts, a planned high-end residential community, and a golf course. GZR would disturb its municipal planning and incur substantial costs in land acquisition and resettlement. Also, the city is close to Guangzhou, and already has a railway link to Guangzhou. Jiangmen supported the idea but did not want to pay for it. Although poorer and of a lower status than the other cities in many respects, Jiangmen was in a position to delay the process of "closing" a deal. 
These disagreements gave rise to scepticism about Zhuhai's political and economic capacity to coordinate the joint project. One interviewee recounted:

One reason why Zhuhai failed to reach consensus with other cities was because of its low administrative status. As a prefecture-level city, it did not have the power to coordinate a project with Guangzhou (a sub-provincial city) as well as Foshan and Jiangmen (two prefecture-level cities). The only remaining option was to lobby the provincial and central governments to intervene because Zhuhai's Party secretary was a key provincial leader. However, with the investment focus on highways, the province was unresponsive to this request. Worse still, Zhuhai and Jiangmen were too restricted by their merger incomes to finance the costly project in full. ${ }^{34}$

However, despite all these uncertainties, the first round of negotiations resulted in a written agreement between Zhuhai, Jiangmen and MOR (but not Guangzhou and Foshan) that specified investment allocation. A GZR Partnership Corporation was established, with a registered capital in cash set at US\$120 million. Zhuhai would contribute 80 per cent, while Jiangmen and MOR would contribute 10 per cent each. ${ }^{35}$ In October 1997, a ceremony was held in Zhuhai to announce the start of the construction work which was expected to be completed by 2001. Not surprisingly, construction soon ground to a halt owing to a lack of capital - Zhuhai, which had pledged to contribute US\$96.8 million, only managed to pay US\$9.6 million, with Jiangmen and MOR adding a meagre US $\$ 400,000$ and US\$970,000, respectively.

To keep the project afloat, Zhuhai lobbied the State Planning Commission and six other ministries for their support. In 1998, the Commission granted the project consent to borrow US\$100 million capital from a Japanese bank and also a permit to issue US\$24 million in bonds. The Commission also made the recommendation to the State Development Bank that a US\$145 million loan be granted to the project. ${ }^{36}$ However, this funding was conditional upon the GZR Partnership Corporation finding US\$121 million in initial funding. At that time, Zhuhai had already amassed a large amount of debt from several controversial, large-scale projects during the $1990 \mathrm{~s},{ }^{37}$ and so it was unable to find the funds needed for GZR. ${ }^{38}$ The project was brought to a deadlock.

In 2000, Zhuhai decided to embark upon another round of negotiations. The process was even tougher than the previous round, as now Foshan's Party secretary had been appointed as a member of the standing committee of the Guangdong Communist Party Committee. Foshan, now having someone in the highest decision-making body of Guangdong, would be more influential in imposing its bargaining constraints. Foshan's leaders continually argued that there was no incentive for them to join the project. ${ }^{39}$ This would cause further delay because the railway had to pass through Foshan's territory. In order to

34 Interview with Zhuhai government official; interview with Zhuhai planner; interview with Guangzhou planner.

35 NDRC 2004.

36 Ibid.

37 See footnote 27.

38 NDRC 2004.

39 Interview with Foshan planning officer, Foshan, August 2009. 
persuade Foshan to cooperate, Zhuhai's Party secretary led a delegation of key officials, including the deputy secretary, mayor and vice mayors, to visit Foshan and Jiangmen. ${ }^{40}$ In Foshan, the delegation met with a group of local leaders for one whole day, but the GZR project was not even mentioned. As one interviewee described it, "the contradiction is sharp." ${ }^{41}$ In Jiangmen, the situation was a bit better. Local officials expressed their full support but still refused to contribute financially. They argued that Jiangmen was not an affluent city and could not afford to fund a costly project. This round of negotiations then came to a dead end. As one interviewee put it, "conflicts that cannot be resolved by individual cities have to be handled by higher levels." 42

The Party secretary of Guangdong then personally went to Foshan to persuade the city's Party secretary to cooperate. The justification was that Foshan should consider regional interests rather than its own economic benefits. Following intervention from such a powerful person, Foshan finally agreed to resume negotiations. However, the suggested route of GZR, as mentioned above, would seriously disturb both Foshan's approved urban master plan and land use plan as it would pass through the city's core and a high-end residential district. This would incur pricey land compensation and resettlement costs which, estimated at US\$363 million, almost equalled the first-phase US\$411 million railway construction costs. ${ }^{43}$ We were told in a 2008 interview that "Foshan has no particular need for the railway; therefore it is not fair for the city to bear the cost without just compensation." 44

Then, a Byzantine process of negotiation occurred: Foshan threatened to not grant a land use permit for GZR, but was finally persuaded to cooperate if two supplementary conditions were satisfied. First, the route had to be modified to avoid passing through the core of the city and the amount of land that required acquisition had to be reduced, even though this might add a further 40 kilometres to the original length. Secondly, Foshan would not contribute any investment, either in cash or land costs. Considering the fact that GZR would not contribute any tangible benefit to Foshan, MOR and Guangdong accepted these supplementary conditions. However, the modified route passed through the city of Jiangmen, which refused to cooperate unless a further modification was made to keep the rail away from the city centre. ${ }^{45}$ Again, this modification increased the rail length and investment required. Jiangmen also refused to fund the project. After much persuasion by provincial leaders and MOR, Jiangmen unwillingly agreed to contribute 5 per cent. One interviewee explained, "Foshan and Jiangmen made demands, knowing that the cost of meeting their desires would

40 Interview with Zhuhai government official.

41 Interview with Zhuhai government official; interview with Zhuhai planner; interview with Guangzhou planner; interview with Foshan planning officer.

42 Interview with Zhuhai government official.

43 NDRC 2004.

44 Interview with Foshan planning officer.

45 Interview with Jiangmen government officer, Jiangmen, August 2009. 
not come from their own pockets, because the majority of expenditures are charged against the budgets of Zhuhai, Guangdong, and MOR."46 The results of these negotiations was that no city gained all they wished for but no city was forced to give up all that was demanded of them either, and the line length and financial expenditure rose more gradually than would have been the case had it proceeded with the initial plan.

The controversies surrounding local opposition reflect the intercity and interscalar political dimensions of GZR. Intercity networking is increasingly used in place of hierarchical command, and decisions are no longer arbitrarily imposed upon localities. Rather, there is a significant increase in the use of bargaining in order to reach consensus. Bargaining occurs between different scales of governments (e.g. the province and Foshan) and between cities of the same or different ranks. Zhuhai could not carry out GZR without the cooperation of the other cities. The lack of formal regulation forces actors to adopt loose and flexible ways to conduct intercity negotiations. With a weak bureaucratic status, Zhuhai failed to persuade other cities to cooperate, but it succeeded in inviting senior leaders to compel and persuade the cities to cooperate. The intervention of higher level authority is contingent upon both internally generated (e.g. Guangdong's economic policies) and externally driven (e.g. inter-region competition) factors. Therefore, it is also one means by which established hierarchies endeavour to insert their functional importance in urban and regional governance. The GZR case also unravels the interaction between intercity and interscalar politics: conflicts have to be resolved among interdependent localities, but when that fails, the vertical interscalar system can facilitate timely and appropriate cooperation.

\section{Investment allocations and project approval}

The problems surrounding investment allocation also highlight interscalar and inter-ministry politics. The first investment agreement was signed in 1997, before Guangdong promised to join the project. This agreement required that Zhuhai should contribute 80 per cent of the US\$120 million registered capital in cash, while Jiangmen and MOR would contribute 10 per cent each. This initial plan failed because Zhuhai was not able to be the lead agency in planning and implementing this expensive, time consuming and politically difficult project. For instance, one interviewee explained, "Zhuhai's financial capacity is weak, and the city leaders wish to invite MOR to be the controlling shareholder so that the new line will be part of the national railway system and will be more financially viable." 47

In 2004, Guangdong and MOR signed an agreement to speed up railway investment in Guangdong under the PMA scheme. GZR was upgraded to a national line under this scheme. An investment sharing deal was then brokered 
after six rounds of province-ministry meetings: MOR became the controlling shareholder (40 per cent of the registered capital in cash), and the two cities of Jiangmen ( 5 per cent) and Zhuhai (30 per cent) would participate by contributing capital and/or land cost. Guangdong provincial government promised to contribute 25 per cent. The remaining capital was to be raised by inviting domestic and overseas investors. All in all, MOR became the lead investment agency.

However, this deal triggered a battle between MOR and NDRC. NDRC disliked the idea of MOR being the controlling shareholder, and threatened not to authorize the project. ${ }^{48}$ It intended to encourage reforms in the railway industry in order to break MOR's monopoly, and to shift the focus of public investment away from the relatively better-off coastal regions and to inland provinces instead. ${ }^{49}$ However, MOR looks set to increase its monopoly, ${ }^{50}$ and Zhuhai saw that it was in its own interests to come under the umbrella of this monopoly. In an interview in 2010, an expert on the railway industry described the situation:

most short and long-distance local and joint venture railways have to link up with existing national railways to carry passengers and cargos between origins and destinations. However, passenger and freight schedule planning of national railways, railroad interlockings and traffic flow are all under the direct control of MOR. Due to capacity constraints, MOR and its regional bureaus have been reluctant to allocate scare network slots to joint ventures. Almost all local and joint venture railroads which are not primarily controlled by MOR have been discriminated against, leading to profit loss. To ensure sufficient cargo flow, Zhuhai struggled to protect the future profit base of GZR, and it has to negotiate long and hard for the best possible solution. ${ }^{51}$

After failing to bring NDRC on board with their plan, MOR, Zhuhai and Guangdong moved to transform the investment sharing scheme. In 2006, a new agreement was signed which required four partners to contribute 40 per cent of the total project cost. MOR was no longer the controlling shareholder and its funding share was reduced from 40 per cent to 20 per cent. Guangdong would take 25 per cent, while Zhuhai and Jiangmen would contribute 50 and 5 per cent, respectively. The remaining investment would be provided by bank loans. However, Zhuhai had concerns about this funding scheme as without MOR as the lead agency, there would be a degree of uncertainty about the project's return. ${ }^{52}$ Despite these reservations, in January 2007, a new GZR company was established, and in September that year, NDRC approved the feasibility study. Construction on the project was soon resumed and, at that time, was estimated to be completed by 2011 .

Other inter-ministry politics also played a role in slowing down the project. The project proposal was not endorsed by either the Ministry of Environmental Protection or the Ministry of Land and Resources as it failed

48 Ibid.

49 Ibid.

50 Interview with five MOR planners and researchers, Beijing, December 2010; interview with well-known university professor, an expert on the railway industry in China, Beijing, June 2009 and July 2010.

51 Interview with well-known university professor, an expert on the railway industry in China, Beijing, December 2010.

52 Interview with Zhuhai officer. 
environmental impact assessments and was the cause of many land disputes. The negotiating process produced a modified plan, in which both the length of the railway and investment required were substantially increased owing to the line being rerouted. The new route was now estimated to cost approximately US $\$ 1.5$ billion, with a distance of 187 kilometres and 11 stations. Increased costs were down to extra track, signalling, earthworks, environmental mitigation (e.g. an extra tunnel was required to protect a nature reserve in Jiangmen) and land acquisition.

The inter-ministry politics involved in the reaching of a consensus in the investment allocation plan and project approval demonstrate that competing central ministries are still important to the functioning of interjurisdictional polity. Specific ministries may have interests and policy preferences which diverge from those of other ministries. Their conflicts intersect in localities to influence urban and regional policy-making, and also redefine the interscalar regime. For example, NDRC refused to allow MOR to be the lead investment agency, which redefined the investment sharing between different hierarchical governments.

\section{Market-led versus state-led?}

In recent years, MOR has frequently put forward the idea of introducing market mechanisms to the railway industry. During the 1990s, when GZR was still proposed as a local joint venture railway, several domestic and overseas investors expressed an interest. One even signed a contract with Zhuhai $^{53}$ that proposed using non-state capital to make up the shortfall. However, all investors withdrew after 2004 when GZR was incorporated into the national railway plan under the PMA scheme. When discussing this, one interviewee explained:

Given the circumstances, non-state investors are required to share investment risks and obligations, but are declined to share rights ... MOR does not easily grant schedules and trackage rights to railway lines which it does not control ... these railroads cannot be independent or get a status equal to the national railway; therefore, interests of non-state investors cannot be guaranteed. ${ }^{54}$

Without a market to match supply and demand, elaborate bargaining has further developed to fill the void. At the time of writing this paper, the negotiation process as detailed above had finished and several major construction works (e.g. bridges and terminals) for this project had been completed. The railroad became operational at the end of 2012 .

\section{Conclusion and Discussion}

This paper attempts to examine interjurisdictional cooperation in China. In particular, it has sought to provide a circumspect appraisal of the institutional dimensions and bargaining politics of such a practice and, in the process, offer

53 Interview with Zhuhai government official.

54 Interview with well-known university professor, an expert on the railway industry in China, Beijing, December 2010 . 
something of a rejoinder to the question as to how a partnership can be developed, sustained or even resisted in a transitional society. Although there is an emerging trend of interjurisdictional partnerships in China, it must be acknowledged that such practices expose a number of dimensions which could conceivably be enhanced. From the case study of GZR, three key themes can be highlighted.

First, interjurisdictional bargaining is a differentiated socio-political process constructed around various places, spaces, and scales in a context-sensible way. It is in this context that we have sought to identify the complexity and bargaining process surrounding the GZR project and four institutional dimensions of making it work among interested parties and across their representative political economic geographies. The case leads to some understanding of the complex processes through which cooperation is achieved. We observe that even once a partnership is formed and adopted, the implementation process is characterized by negotiation among and between levels of the hierarchy. Each agent aims to steer the plan in a direction favourable to its own interests. The outcome may not be as originally intended, but it is worked out through extensive bargaining.

Secondly, in unravelling the politically constructed nature of the emerging interjurisdictional regime, we are witnessing a recomposition or qualitative reorganization of the regime. Inter-ministry politics demonstrates a range of competitive central interests which intersect at provincial and city level to influence urban and regional policy making. Interscalar relations have been fundamentally redefined. Top-down hierarchical dominance in decision making has been denaturalized, while local governments can influence policy decisions through their political and economic resources. In terms of intercity politics, cities which are not connected with each other have to seek partnership in order to overcome hurdles in capital accumulation. Because the institutional framework for horizontal networking is poorly developed, they need to play a more active role in partnership building and must resolve conflicts through extensive bargaining. We also note a bargaining between the state and the market. The state would like to use the market to externalize its responsibility of building costly projects and resolve its capital shortage crisis. This is totally different from the pre-reform state regime. However, state-market relations did not work out in the GZR case because non-state investors were asked to share risks and obligations, but were not allowed to benefit from rights under MOR's monopoly. In a sense, bargaining, rather than being on the decline in the post-reform era, has become compulsory, and is increasingly intensified in order to fill the institutional void in a highly fragmented political environment.

Thirdly, we have also examined how the historical contingencies and pathdependencies of a transitional society define and configure partnership building. Under the conditions of intensified economic decentralization and without a proper legal framework, high level governments are still capable of exerting their influence over local and regional growth. This complicates interscalar relations. For example, Guangdong forced Foshan to release land for GZR. 
Top authorities can determine local government behaviour by altering opportunities and constraints on collective actions. Various actors opt for irregular and ad hoc procedures to resolve conflicts, allowing room for externalities, such as informal contacts, political wills, and factors like unequal urban status and guanxi, as indicated in the case study. In particular, the strong influence of political wills complicates project negotiation and selection processes. Theoretically, each government adheres to its own cost-benefit criteria for project acceptance, but joint projects may well be constrained by contextually specific non-economic factors. GZR is a good example. Zhuhai's Party secretary went beyond economic logic to kick-start the project. The intervention of senior officials from top authorities made the collaboration possible, even when the majority of participants had no economic incentive to do so. However, an individual-driven collaboration increases the political risk, because the party who agrees to cooperate may not be the one in charge of its implementation in the future. A combination of these factors will subject joint projects to extensive assessments and consultation, endless (re)negotiation, stonewalling, and even withdrawal from agreement. Our study also suggests that intervention from the state or politicians is less shaped by economic logic and formal institution and more by the same political conflicts (e.g. conflicts between and among different territorial administrations and competitive bureaucracies) that they are supposed to help alleviate.

In this case study, we have revealed that interjurisdictional cooperation has unique characteristics in the context of economic transition, because the state can go beyond economic logic, manipulate market orders, and legitimize itself by prioritizing development. This is reflected in inter-ministry politics, interscalar relations, intercity politics, and state-market relations. GZR is a particularly interesting case. On one hand, China's railroads have been traditionally managed by MOR in a highly centralized manner. On the other hand, facing severe rail capacity constraints and little freedom to change the situation, provinces and cities have to call on MOR to finance, build and operate joint venture railways. MOR welcomes such a move because it means a reduction of its financial obligations with little loss of its authority. In a sense, the railway monopoly and rapid expansion have coincided with a severe shortage of capital and thus the urgency for the involvement of localities and market players. This situation has complicated joint railway projects, pushing all kinds of bargaining politics to the extreme. It also allows significant room for established hierarchies to insert their functional importance and avoid takeovers by market forces.

All in all, we show that path-dependencies can provide current political forces with more, rather than fewer, instruments with which to negotiate economic trajectories and thus impose greater influence over local and regional governance. Bargaining is being used as a strategy for this purpose. Until there is a legal framework for interjurisdictional cooperation, bargaining may remain as the main method in consensus building. From a broader perspective, a growing direct interaction between cities may lead to widely shared values, procedures and norms in interjurisdictional cooperation. Whether or not this can develop into a legal 
framework remains to be seen. Yet, future studies of new cooperation practices should be significantly advanced to reveal the currently unfolding regional initiatives in China.

\section{References}

Bollens, John C., and Henry J. Schmandt. 1982. The Metropolis: Its People, Politics, and Economic Life (4th ed). New York: Harper \& Row.

Lampton, David M. 1992. "A plum for a peach: bargaining, interest, and bureaucratic politics in China." In Kenneth G. Lieberthal and David M. Lampton (eds.), Bureaucracy, Politics, and Decision Making in Post-Mao China. Oxford: University of California Press, 33-58.

Lieberthal, Kenneth G., and David M. Lampton. 1992. Bureaucracy, Politics, and Decision Making in Post-Mao China. Oxford: University of California Press.

Lieberthal, Kenneth G., and Michel Oksenberg. 1988. Policy Making in China: Leaders, Structures and Processes. Princeton: Princeton University Press.

Luger, Katrin. 2008. Chinese Railways: Reform and Efficiency Improvement Opportunities. Springer: Physica-Verlage.

Luo, Xiaolong, and Jianfa Shen. 2006. "Kuajie de chengshi zengzhang: yi Jiangyin jingji kaifaqu Jingjiang yuanqu weili" (Urban growth between cities: the case of Jiangyin Economic Development Zone in Jingjiang). Dili xuebao (Acta Geographica Sinica) 61(4), 435-445.

NDRC. 2004. Zhuhai tielu he chengji tielu fazhan guihua (Rail and intercity rail development plan in Zhuhai). Beijing: Unpublished government document.

Wu, Fulong, Jiang Xu and Anthony Gar-On Yeh. 2007. Urban Development in Post-Reform China: State, Market and Space. London and New York: Routledge.

$\mathrm{Xu}$, Jiang. 2008. "Governing city regions in China: theoretical discourses and perspectives for regional strategic planning." Town Planning Review 79(2-3), 157-185.

$\mathrm{Xu}$, Jiang, and Anthony Gar-On Yeh. 2005. "City repositioning and competitiveness building in regional development: new development strategies of Guangzhou, China.” International Journal of Urban and Regional Research 29, 283-308.

Yeung, Yue-Man, Jianfa Shen and Li Zhang. 2005. The Western Pearl River Delta: Growth and Opportunities for Cooperative Development with Hong Kong. Hong Kong: Hong Kong Institute of Asia-Pacific Studies.

Zhang, Jingxiang, and Fulong Wu. 2004. "Cong xingzheng qu jianbing dao quyu guanzhi Changjiang sanjiaozhou de shizheng yu sikao" (From administrative merger to regional governance: pondering upon experiences in the Yangtze River Delta). Chengshi guihua 28(5), 25-30.

Zhang, Jingxiang, and Fulong Wu. 2006. "China's changing economic governance: administrative annexation and the reorganization of local governments in the Yangtze River Delta." Regional Studies 40(1), 3-21.

Zhao, Yanjing. 2002. "Cong chengshi guanli zouxiang chengshi jingying” (From urban management towards urban entrepreneurialism). Chengshi guihua 26(11), 7-15. 